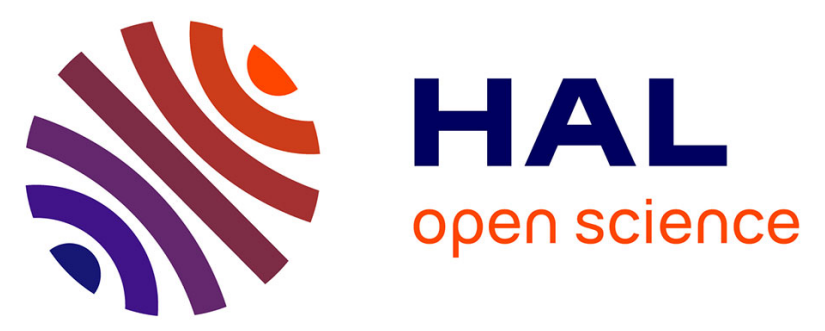

\title{
Point Defects Modeling Explains Multiple Sulfur Species in Sulfur-Doped Na4(Al3Si3O12)Cl Sodalite
}

Adrien Stoliaroff, Romain Schira, Féodor Blumentritt, Emmanuel Fritsch, Stéphane Jobic, Camille Latouche

\section{- To cite this version:}

Adrien Stoliaroff, Romain Schira, Féodor Blumentritt, Emmanuel Fritsch, Stéphane Jobic, et al.. Point Defects Modeling Explains Multiple Sulfur Species in Sulfur-Doped Na4(Al3Si3O12)Cl Sodalite. Journal of Physical Chemistry C, 2021, 125 (30), pp.16674-16680. 10.1021/acs.jpcc.1c02423 . hal03355987

\section{HAL Id: hal-03355987 \\ https://hal.science/hal-03355987}

Submitted on 8 Oct 2021

HAL is a multi-disciplinary open access archive for the deposit and dissemination of scientific research documents, whether they are published or not. The documents may come from teaching and research institutions in France or abroad, or from public or private research centers.
L'archive ouverte pluridisciplinaire HAL, est destinée au dépôt et à la diffusion de documents scientifiques de niveau recherche, publiés ou non, émanant des établissements d'enseignement et de recherche français ou étrangers, des laboratoires publics ou privés. 


\title{
Point Defects Modelling Explains Multiple Sulfur Species in Sulfur-doped $\mathrm{Na}_{4}\left(\mathrm{Al}_{3} \mathrm{Si}_{3} \mathrm{O}_{12}\right) \mathrm{Cl}$ Sodalite
}

Adrien Stoliaroff ${ }^{1}$, Romain Schira ${ }^{1}$, Féodor Blumentritt ${ }^{1}$, Emmanuel Fritsch ${ }^{1}$, Stéphane Jobic ${ }^{* 1}$, Camille Latouche*1

${ }^{1}$ Université de Nantes, CNRS, Institut des Matériaux Jean Rouxel, IMN, F-44000 Nantes, France

camille.latouche@cnrs-imn.fr

stephane.jobic@cnrs-imn.fr

\begin{abstract}
Colorless $\mathrm{Na}_{4}\left(\mathrm{Al}_{3} \mathrm{Si}_{3} \mathrm{O}_{12}\right) \mathrm{Cl}$ sodalite exhibits the propensity to host sulfur atoms that give rise to interesting optical properties. Namely, the observed color, the luminescence and the photochromism properties are commonly associated with the presence of specific $\left(\mathrm{S}_{\mathrm{n}}\right)^{\mathrm{x}-}$ species $(\mathrm{n}=$ 2 or $3 ; x=1$ or 2 ) trapped in the host lattice concomitantly with chlorine vacancies, when needed for charge balance. In this paper we present a theoretical investigation of the native point defects and some sulfur-based point defects that may form in sodalite. DFT calculations were used to simulate the formation energies of possible defects in different states of charge, together with their relative transition energy levels and concentrations. Our results unambiguously demonstrate that sulfur ions may easily replace chloride in sodalite at various oxidation states for a low energy cost. This accounts for the difficulties to identify $\left(\mathrm{S}_{2}\right)$ and $\left(\mathrm{S}_{3}\right)$ species in the material for instance. This study is also the first one on defect formation energy with a full determination of the stability domain on a senary system $(\mathrm{Na} / \mathrm{Al} / \mathrm{Si} / \mathrm{O} / \mathrm{Cl}$ and S).
\end{abstract}




\section{Introduction}

Sodalite is a natural aluminosilicate with various optical properties often induced by the presence of intrinsic, extrinsic or complex defects ${ }^{1,2}$. Many of them are linked directly to sulfur or sulfur-related defects. Hence, the observed blue hue would originate from $\left(\mathrm{S}_{3}\right)$-trimers ${ }^{3,4}$, the yellow one from $\left(\mathrm{S}_{2}\right)$-dimers 5 , the green color from the coexistence of $\left(\mathrm{S}_{2}\right)^{-}$dimers and $\left(\mathrm{S}_{3}\right)^{-}$ trimers ${ }^{5-7}$ and the red tint possibly from $\left(\mathrm{S}_{4}\right)$ - tetramers ${ }^{3,8}$, the $\left(\mathrm{S}_{\mathrm{n}}\right)^{-}$- species playing the role of chromophores. Sodalite may also show an impressive orange luminescence. This one is correlated to the presence of $\left(\mathrm{S}_{2}\right)^{-}$single charged pairs in its structure 9 . Another noteworthy property seen in sodalite is photochromism, i.e. a reversible change of the absorption spectrum upon ultraviolet (UV) illumination (the photochromic variety of sodalite is commonly called hackmanite). Such a property is associated to the photo-ionization of $\left(\mathrm{S}_{n}\right)^{2-}$ species (presumably $\mathrm{n}=2$ ) with transfer of one electron towards a single charged chlorine vacancy (i.e. electron transfer from the $\left(\mathrm{S}_{\mathrm{n}}\right)^{\prime} \mathrm{Cl}^{-}$ $\mathrm{V}_{\mathrm{Cl}}^{\circ}$ complex defects to the $\left(\mathrm{S}_{\mathrm{n}}\right)^{\mathrm{x}} \mathrm{Cl}-\mathrm{V} \mathrm{x}_{\mathrm{Cl}}$ ones where the ', ${ }^{\circ}$ and $\mathrm{x}$ superscripts refer to the Kroger-Vink notation. ${ }^{10,11}$ The trapped electrons, spatially confined to the $\mathrm{Cl}$ vacancy and its surrounding, can then absorb in the visible range triggering the color change of hackmanite accompanied by the orange sulfurrelated emission. The final photo-generated hue is strongly dependent on the chemical composition of the sodalite, namely the nature of the halide $\left(\mathrm{Cl}^{-}, \mathrm{Br}^{-}\right.$or $\left.\mathrm{I}^{-}\right)$and the chalcogen introduced as dopants ( $\mathrm{S}$, Se or Te). 11-15Thus, hackmanite appears as a good candidate for many anthropic applications as optical memory material for example. ${ }^{16}$

Despite the huge amount of experimental and theoretical results already collected on properties of sodalite and hackmanite, no article reports so far on the energetic cost to form specific point defects in sodalite, and especially sulfur-related defects. The present study aims at filling this gap by studying the formation energies of different intrinsic point defects $\left(\mathrm{V}_{0}, \mathrm{~V}_{\mathrm{Na}}, \mathrm{V}_{\mathrm{Cl}}, \mathrm{Si}_{\mathrm{Al}}\right.$ and $\left.\mathrm{Al}_{\mathrm{Si}}\right)$, extrinsic point defects $\left(\mathrm{S}_{\mathrm{Cl}},\left(\mathrm{S}_{2}\right)_{\mathrm{Cl}},\left(\mathrm{S}_{3}\right)_{\mathrm{Cl}}\right.$ and $\left.\left(\mathrm{SO}_{4}\right)_{\mathrm{Cl}}\right)$ and complex defects $\left(\mathrm{V}_{\mathrm{Cl}}+\mathrm{S}_{\mathrm{Cl}}, \mathrm{V}_{\mathrm{Cl}}+\left(\mathrm{S}_{2}\right)_{\mathrm{Cl}}\right.$ and $\left.\mathrm{V}_{\mathrm{Cl}}+\left(\mathrm{S}_{3}\right)_{\mathrm{Cl}}\right)$. We determined for the first time the stability domain of sodalite, its defect formation energies with respect to different synthesis conditions, and the impact of defects on the electronic structure of the ideal $\mathrm{Na}_{4}\left(\mathrm{Al}_{3} \mathrm{Si}_{3} \mathrm{O}_{12}\right) \mathrm{Cl}$ sodalite material together with estimated defects concentrations. In addition, to the knowledge of the authors, this is the first time that defect formation energies and stability domain are determined for a senary system (Na-Al-Si-O-Cl and $\mathrm{S}$ as additional extrinsic defects). In that context, a general algorithm is proposed in SI to determine chemical potentials irrespective of the number of chemical species composing the host compound.

\section{Computational details}

\section{Electronic computations}

First DFT calculations were performed using VASP 17-19 (Vienna Ab-initio Simulation Package) and the PBE 20 functional within the Projector Augmented-Wave scheme (PAW) and completed by HSE@PBE calculations for a better estimation of the gap. 21 The energy cutoff was set to $550 \mathrm{eV}$. Firstly, we studied the pristine cell for accurate bandgaps and single point defect calculations. Geometry of the pristine and faulted cells with single point defects were performed by sampling the first
Brillouin zone following a $8 \times 8 \times 8$ Monkhorst-Pack mesh. The energy and force convergence thresholds were set to $10^{-6} \mathrm{eV}$ and $5 \times 10^{-3} \mathrm{eV} / \AA$ for the self-consistent cycle, respectively. Accurate energy calculations were performed with a $6 \times 6 \times 6 \Gamma$-centered $\mathrm{k}$ mesh. Since the unary cell was already quite large (46 atoms, $\sim 9$ $\AA$ Acell parameter) we did not build a larger cell for simple point defects. On the contrary, complexes defects have been studied using $2 \times 1 \times 1$ supercells ( 92 atoms) to ensure a reasonable spacing between the defect complexes and their periodic images. A $2 \times 4 \times 4 \mathrm{k}$-mesh was used for both optimization and accurate energy calculations of the complexes. Thresholds of $10^{-6} \mathrm{eV}$ and $10^{-2} \mathrm{eV} / \AA$ were taken for energy and force convergence, respectively. A $\Gamma$-centered k-mesh of the same size was used for accurate energy calculations. For the pristine cell, the band gap was refined using the HSE functional on top of the relaxed PBE structure using a $4 \times 4 \times 4 \mathrm{k}$-mesh (calculated gap of $6.52 \mathrm{eV}$ for HSE@PBE vs. $4.75 \mathrm{eV}$ for PBE to compare with experimental gap estimated at ca. $7 \mathrm{eV}$ from investigation at a synchrotron). ${ }^{22}$ This result allows us determine the band edge shifts. All posttreatments were performed with our in-house software PyDEF. 23,24

\section{Defect formation formalism}

Defect Formation Enthalpies (DFE) $\Delta H$ with respect to electronic potential $\mu_{\mathrm{E}_{\mathrm{F}}}$ were computed using the following the equation

$$
\begin{aligned}
\Delta \mathrm{H}_{\text {form }}^{\mathrm{D}, \mathrm{q}}\left(\mu_{\mathrm{E}_{\mathrm{F}}}\right)=\mathrm{E}_{\mathrm{total}}^{\mathrm{D}, \mathrm{q}}-\mathrm{E}_{\text {total }}^{\text {host }} & \\
& +\sum_{X_{i}} n_{X_{i}}\left(\mu_{X_{i}}^{0}+\Delta \mu_{X_{i}}\right)+q\left(E_{V B M}^{\text {host }}+\mu_{E_{F}}\right) \\
& +\operatorname{corr}(D, q)
\end{aligned}
$$

where

- $E_{\text {total }}^{\mathrm{D}, \mathrm{q}}$ is the total energy of the faulted supercell (the supercell which contains the defect) after relaxation of the atomic positions without symmetry constrains at fixed cell parameters - $E_{\text {total }}^{\text {host }}$ is the total energy of the host supercell (the pristine structure)

- $\mu_{\mathrm{X}_{i}}{ }^{0}$ is the chemical potential of element $X_{i}$ in its standard phase (ambient conditions)

- $\Delta \mu_{X}$ is the variation of the chemical potential of element $\mathrm{X}_{\mathrm{i}}$ from its chemical potential in the thermodynamic standard phase $\left(\Delta \mu_{X}<0\right)$, induced by the crystal growth conditions as detailed in the next paragraph

- $\mathrm{n}_{\mathrm{X}_{i}}$ is the number of atoms of species $\mathrm{X}_{\mathrm{i}}$ added/removed from the ideal lattice to form the defect. The sign is positive for removed species and negative for added species.

- $E_{V B M}^{\text {host }}$ is the energy of the valence band maximum (VBM). It is the reference energy for $\mu_{E_{F}}$

- $\mu_{E_{F}}$ is the chemical potential of the electron reservoir, that fixes the Fermi level.

- $\operatorname{corr}(D, q)$ corresponds to various energy corrections to take into account. Namely, potential alignment, band edges, MakovPayne-like, Moss-Burstein band filling and Perturbed Host States (PHS) corrections are incorporated into the $\operatorname{corr}(D, q)$ term.

As the Fermi level $\mu_{E_{F}}$ takes values between the Valence Band Maximum (VBM) and the Conduction Band Minimum (CBM), one needs to correctly assess the bandgap. Since the computed gap is often badly reproduced in GGA, a calculation on top of the relaxed structure using a more refined functional is mandatory (here HSE06). This calculation increases the gap and adds the 
band shifts corrections via the $\Delta \mathrm{Ev}$ and $\Delta \mathrm{E}_{\mathrm{c}}$ terms, being for the Valence Band and the Conduction Band, respectively.

In our study, the computed bandgap in GGA is $4.75 \mathrm{eV}$. Using a more refined model (HSE06), which known to better reproduce the electronic structure, the bandgap becomes $6.65 \mathrm{eV} .{ }^{25}$

The electrostatic potential is shifted by an unknown value after the introduction of a charge in the cell. 26,27 To recalibrate the charged cells energies, the DFE is corrected by the averaged difference between the potential felt by the atoms far from the defect $\mathrm{V}_{D, q}^{\mathrm{r}}$ and the potential in the ideal cell $\mathrm{V}_{\text {host }}^{\mathrm{r}}$ weighted by the defect charge. This is referred to the Potential Alignment (PA) correction and is given by the following equation:

With

$$
\Delta E_{P A}=q \times \overline{\Delta \mathrm{V}} \text {. }
$$

$$
\overline{\Delta \mathrm{V}}=V_{D, q}^{r}-V_{\text {host }}^{r}
$$

A cell large enough to reproduce realistic defect concentrations cannot be used due to finite computational power.

The faulted cells which can be realistically studied have to be much smaller. Physically, the Moss-Burstein band-filling effect is known to happen in heavily doped semiconductors, i.e. low effective mass charge carriers thermally fill the bottom(top) of the conduction(valence) band for a $n(p)$-type semiconductor. 28,29 This can artificially be the case in (too) small supercells considered. If so, one needs to correct this artifact by applying the following energetic equations:

$$
\left\{\begin{array}{c}
\Delta E_{M B}^{e^{-}}=-\sum_{n, \boldsymbol{k}} \omega_{\boldsymbol{k}} \eta_{n, \boldsymbol{k}} \widetilde{E_{n, \boldsymbol{k}}^{C B M}} \mathcal{H}\left(\widetilde{E_{n, \boldsymbol{k}}^{C B M}}\right) \\
\Delta E_{M B}^{h^{+}}=-\sum_{n, \boldsymbol{k}} \omega_{\boldsymbol{k}}\left(2-\eta_{n, \boldsymbol{k}}\right) \widetilde{E_{n, \boldsymbol{k}}^{V B M}} \mathcal{H}\left(\widetilde{E_{n, \boldsymbol{k}}^{V B M}}\right)
\end{array}\right.
$$

where

$$
\left\{\begin{array}{l}
\widetilde{E_{n, \boldsymbol{k}}^{C B M}}=\mathrm{E}_{\mathrm{n}, \mathbf{k}}-\left(\mathrm{E}_{\mathrm{CBM}}^{\mathrm{H}}+\overline{\Delta \mathrm{V}}\right) \\
\widetilde{E_{n, \boldsymbol{k}}^{V B M}}=\left(\mathrm{E}_{\mathrm{VBM}}^{\mathrm{H}}+\overline{\Delta \mathrm{V}}\right)-\mathrm{E}_{\mathrm{n}, \mathbf{k}}
\end{array}\right.
$$

and the $n$ index refers to a summation over the bands, $\boldsymbol{k}$ a summation over the k-points, $\omega_{\boldsymbol{k}}$ the $k^{\text {th }} \mathrm{k}$-point weight, $E_{n, \boldsymbol{k}}$ the $n^{\text {th }}$ band energy at the $k^{\text {th }} \mathrm{k}$-point in the faulted cell, $\eta_{n, k}$ is the occupation of the $n^{\text {th }}$ band at k-point $\boldsymbol{k}$ and $\mathcal{H}$ is the Heaviside function. It expresses the removal of the spuriously filled energy levels at the top of the valence band and the bottom of the conduction band.

In the real material, point defects are well separated from one another, whereas in the supercell model, the defect may be subject to electrostatic interactions from its periodic images in the neighboring cells. In order to eliminate this artefact, we use Makov-Payne-like correction ${ }^{26}$ expressed as

$$
\Delta E_{M P}=\left(1+c_{s h}\left(1-\epsilon^{-1}\right)\right) \frac{q^{2} \alpha_{M}}{2 \epsilon V^{\frac{1}{3}}},
$$

where $c_{s h}$ is a geometry dependent factor, $\epsilon$ is the dielectric constant of the material and $\alpha_{M}$ the Madelung constant. Lany and Zunger propose a list of specific values of $c_{s h}$ for generic structural types. Here, the body-centered cubic value of -0.342 is used.

In the case of a finite supercell approach, energy levels (bands) of the host can be affected by the presence of shallow defect levels in the band gap. The spuriously formed Perturbed Host States (PHS) need to be accounted for. The accuracy is improved by the following correction

$$
\Delta E_{P H S}=z_{e}-\Delta E_{C}-z_{h^{+}} \Delta E_{V}
$$

where $z_{e^{-}}$is the number of electrons artificially introduced in the CB and $z_{h^{+}}$of holes in the VB. ${ }^{30}$

The defect transition energy levels, hereafter labeled $\varepsilon\left(q / q^{\prime}\right)$ correspond to the values of the Fermi level for which the formation energy of a charge state $q$ is equal to the formation energy of a charge state $q^{\prime}$. Consequently, the $\varepsilon\left(q / q^{\prime}\right)$ indicates the transition level where the defect in the charge states $q$ and $q^{\prime}$ are isoenergetics (i.e. in the same amount). It follows the equation:

$$
\varepsilon\left(q / q^{\prime}\right)=\frac{\Delta \mathrm{H}_{\text {form }}^{\mathrm{D}, \mathrm{q}}(0)-\Delta \mathrm{H}_{\text {form }}^{\mathrm{D}, \mathrm{q}^{\prime}}(0)}{q-q^{\prime}}
$$

Since the determination of the effective masses is mandatory to obtain the Fermi level and the defect concentrations (see SI), the electron and hole effective masses $\left(m_{e}^{*}\right.$ and $\left.m_{h}^{*}\right)$ were calculated by fitting the CBM and the VBM of the band diagram of the hypothetical perfect structure material using the parabolic relation:

$$
E(\boldsymbol{k})=E_{0} \pm \frac{\hbar^{2}}{2 m^{*}} k^{2}
$$

$m_{e}^{*}$ and $m_{h}^{*}$ were estimated at $0.55 m_{e}$ and $7.10 m_{e}$, respectively (in the PBE approximation), i.e. a hole effective mass ten times larger than the electron one.

Concentration $\mathrm{n}_{\mathrm{D}}$ of the defect $\mathrm{D}$ as a function of the temperature during the synthesis $\mathrm{T}_{\text {grow }}$ can be estimated by applying Boltzmann statistics. Namely, we compute

$$
n_{D}\left(E_{F}^{\text {grow }}\right)=N_{D}^{\text {sites }} e^{-\frac{\Delta H_{\text {form }}^{D}\left(E_{F}^{\text {grow }}\right)}{k_{B} T_{\text {grow }}}}
$$

where $k_{B}$ is the Boltzmann constant, $N_{D}^{\text {sites }}$ the number of sites available for the defect, and $E_{F}^{\text {grow }}$ is the Fermi level during the synthesis. The material is globally charge neutral. This sets the value of the Fermi level so that to compensate the charges of the carriers (electrons and holes) with the ones of the defect. If $n_{e}$ and $n_{h}$ are the electron and holes concentration at a given temperature, respectively, the aforementioned condition can be written as:

$$
-n_{e}\left(E_{F}^{\text {grow }}\right)+n_{h}\left(E_{F}^{\text {grow }}\right)+\sum_{D} q_{D} \cdot n_{D}\left(E_{F}^{\text {grow }}\right)=0
$$

where $n_{e}$ and $n_{h}$ are computed through the Fermi-Dirac function.

We focused on a wide range of temperatures which includes the experimental synthesis temperature ( $c a .1200 \mathrm{~K}$ ) (effective masses may have an impact on the calculated concentrations of defects (see SI). Consequently, the absolute values of these ones have to be considered here with caution. Nevertheless, calculations give a good overview of the relative concentrations of defects).

\section{Result and discussion}

\section{Pristine Cell}

The $\mathrm{Na}_{4}\left(\mathrm{Al}_{3} \mathrm{Si}_{3} \mathrm{O}_{12}\right) \mathrm{Cl}$ sodalite crystallizes within a cubic lattice $\left(P-43 n, n^{\circ} 218\right)$ with two formula units (i.e. 46 atoms) per cell. Its framework consists in $0 \mathrm{D}$ - $\beta$-cages $\left(\mathrm{Al}_{12} \mathrm{Si}_{12} \mathrm{O}_{60}\right.$ sphere-like entities built upon alternating corner sharing [ $\left.\mathrm{SiO}_{4}\right]$ and $\left[\mathrm{AlO}_{4}\right]$ tetrahedral) (Fig. 1a and $\mathbf{1 b}$ ) that condense to form $a$ 
tridimensional $\left[\mathrm{Al}_{3} \mathrm{Si}_{3} \mathrm{O}_{12}\right]^{3-}$ network (Fig. 1c) where each cage is nominally filled by a sodium tetrahedron containing a chlorine atom (Fig. 1d). Optical properties of hackmanite are associated to the partial substitution of $\mathrm{Cl}^{-}$by sulfur based anionic species, some of them coexisting systematically in the same material as highlighted by the X-ray photoelectron spectrum of Figure 2.
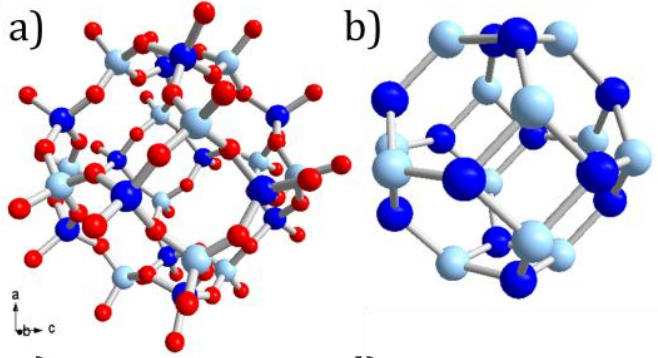

c)
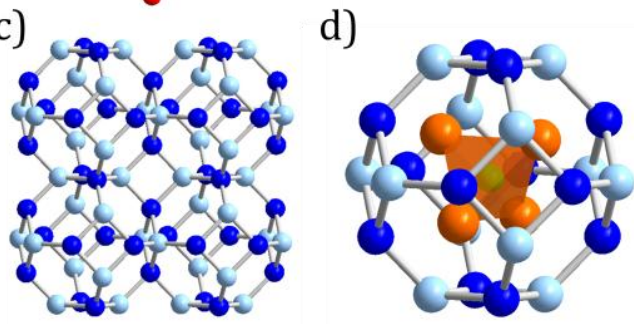

Figure 1. a) Representation of the $\beta$-cage, building entity of the sodalite framework, b) schematic representation of the $\beta$-cage where [SiO 4 and $\left[\mathrm{AlO}_{4}\right]$ tetrahedra are represented by point spheres; c) Schematic representation of the aluminosilicate framework of the sodalite structure; $d) \beta$-cage with the [ClNa 4 tetrahedron encapsulated in it. Chlorine, sodium, aluminum, silicon and oxygen atoms are represented in green, orange, light blue, dark blue and red, respectively.

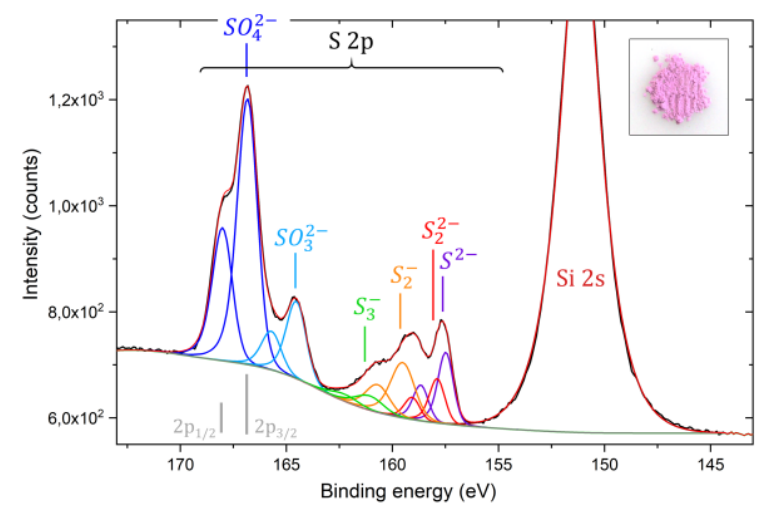

Figure 2. XPS spectrum of a synthetic hackmanite in its purple, excited state with tentative assignments of (unpublished results $S$ $2 p_{1 / 2}, S 2 p_{3 / 2}$ ) bands.

\section{Stability domain of sodalite}

To accurately determine the defect formation energies, it is mandatory to capture the crystal growth conditions. This is done through the so-called chemical potentials values. The DFE depend linearly on the chemical potentials values, so that they are the numerical parameters bearing the heaviest numerical weight on the results. Thus, the limits of the stability domain of the host material are computed with respect to the chemical potentials. Here, 18 phases were considered, namely the 6 thermodynamic reference phases for the chemical elements $\left(\mathrm{Na}_{(s)}, \mathrm{Al}_{(s)}, \mathrm{Si}_{(s)}, \mathrm{S}_{(s)}, \mathrm{Cl}_{2(g)}\right.$ and $\left.\mathrm{O}_{2(g)}\right)$, and also quartz $\mathrm{SiO}_{2}$, alumina $\mathrm{Al}_{2} \mathrm{O}_{3}, \mathrm{NaCl}$, other alumino-silicate minerals such as $\mathrm{NaAlSi}_{3} \mathrm{O}_{8}$ (albite) and $\mathrm{Al}_{2} \mathrm{O}\left(\mathrm{SiO}_{4}\right)$ (andalusite), $\mathrm{Na}_{2} \mathrm{Si}_{2} \mathrm{O}_{5}$, $\mathrm{NaAlSi}_{2} \mathrm{O}_{6}, \mathrm{Na}_{2} \mathrm{~S}, \mathrm{NaAlCl}_{4}, \mathrm{AlCl}_{3}, \mathrm{NaAlSi}$ and $\mathrm{Na}_{2} \mathrm{SO}_{4}$. As the considered material implies the possible incorporation of (poly)sulfides, the sulfur was considered for all synthesis conditions and defects. This leads to a senary material $\mathrm{Na}_{4}\left(\mathrm{Al}_{3} \mathrm{Si}_{3} \mathrm{O}_{12}\right) \mathrm{Cl}: \mathrm{S}$ and we used our preexisting protocol to determine the different synthesis conditions. ${ }^{31}$

The chemical potential values used throughout our study are summarized in Table 1. Given the reactants $\mathrm{SiO}_{2}$ and $\mathrm{Al}_{2} \mathrm{O}_{3}$, the strong stability of the alumino-silicate framework and our knowledge of the coloration mechanism, oxygen-poor conditions seem at first sight highly unrealistic and are ignored here. The main focus is sulfur doping, thus the attention is set on the anions, and more specifically on the sulfur vs. chlorine balance. From the study of the stability domain, two main synthesis conditions can be distinguished. The first one, hereafter labelled $\boldsymbol{A}$, corresponds to a S-rich/Cl-poor situation. The second condition considered $(\boldsymbol{B})$ is S-poor/Cl-rich and should be

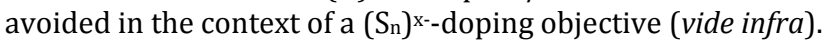

Table 1. Synthesis conditions considered in this study in terms of chemical potential deviations from the reference thermodynamic species $\Delta \mu(\mathrm{eV})$. A stands for (S rich/Cl poor, O medium), B for ( $S$ poor/Cl-rich, O-rich) (top). Reference chemical potentials calculated with the PBE functional (bottom).

\begin{tabular}{ccccccc}
$\begin{array}{c}\text { Synthesis } \\
\text { condition }\end{array}$ & $\boldsymbol{\Delta} \boldsymbol{\mu}_{\mathbf{S}}$ & $\boldsymbol{\Delta} \boldsymbol{\mu}_{\mathrm{Cl}}$ & $\boldsymbol{\Delta} \boldsymbol{\mu}_{\mathbf{0}}$ & $\boldsymbol{\Delta} \boldsymbol{\mu}_{\mathbf{S i}}$ & $\boldsymbol{\Delta} \boldsymbol{\mu}_{\mathrm{Al}}$ & $\boldsymbol{\Delta} \boldsymbol{\mu}_{\mathbf{N a}}$ \\
\hline $\mathrm{A}$ & 0.00 & -2.40 & -2.80 & -3.00 & -3.61 & -1.77 \\
$\mathrm{~B}$ & -6.30 & -0.60 & 0.00 & -8.46 & -7.82 & -3.37 \\
\hline $\mathbf{X}_{\mathbf{i}}$ & $\mathbf{S}$ & $\mathbf{C l}$ & $\mathbf{0}$ & $\mathbf{S i}$ & $\mathbf{A l}$ & $\mathbf{N a}$ \\
\hline$\mu_{X_{i}}^{0}(\mathrm{eV})$ & -4.13 & -1.79 & -4.93 & -5.42 & -3.70 & -1.28 \\
\hline
\end{tabular}

\section{Simple point defects}

Based on the aforementioned details, it is now possible to discuss the simple point defects present in the targeted material. Let us start the analysis with the $\boldsymbol{A}$ synthesis conditions (Figure 3).

In these synthesis conditions, the intrinsic donor defects with the negative formation enthalpies are $V_{C l}$ and $S i_{A l}$ until $\mu_{E_{F}} \sim 3.5$ $\mathrm{eV}$ and $\mathrm{V}_{\mathrm{Na}}$ and $\mathrm{Al}_{\mathrm{Si}}$ for $\mu_{E_{F}}$ higher than $\sim 5 \mathrm{eV}$. These defects clearly delimit the dopability domain of $\mathrm{Na}_{4}\left(\mathrm{Al}_{3} \mathrm{Si}_{3} \mathrm{O}_{12}\right) \mathrm{Cl}$, that is the energy window that entraps the Fermi level for the undoped material as well as its doped variants (e.g. doped with S). In that domain, it is striking to observe that the formation enthalpies $\Delta \mathrm{H}(q=0)$ calculated for the three (poly)sulfide substituting chlorine defects, i.e. $S_{C l}, S_{2_{C l}}$ and $S_{3_{C l}}$, are quite similar and lower than $1.5 \mathrm{eV}$. Consequently, high concentrations are expected for these three defects for $S$ doped materials (as well as for the chlorine and sodium vacancies) based on energy criteria, and it appears highly likely that the aforementioned sulfur species will (systematically) coexist in S-doped sodalite. Furthermore, it is worth noticing that the $0 /-1$ transition levels (i.e. redox potentials between $\mathrm{S}_{\mathrm{n}^{-}}$and $\mathrm{S}_{\mathrm{n}^{2-}}$ species) of $S_{C l}, S_{2_{C l}}$ and $S_{3_{C l}}$ are located in the mid gap region in a quite restricted energy domain (at 3.41, 4.61 and $4.29 \mathrm{eV}$ above the valence band, respectively), Of course the evolution of the Fermi level with respect to the temperature will favor a given electronic configuration of (poly)sulfide anions over another. The situation may gain in complexity under UV or X-ray excitation. 

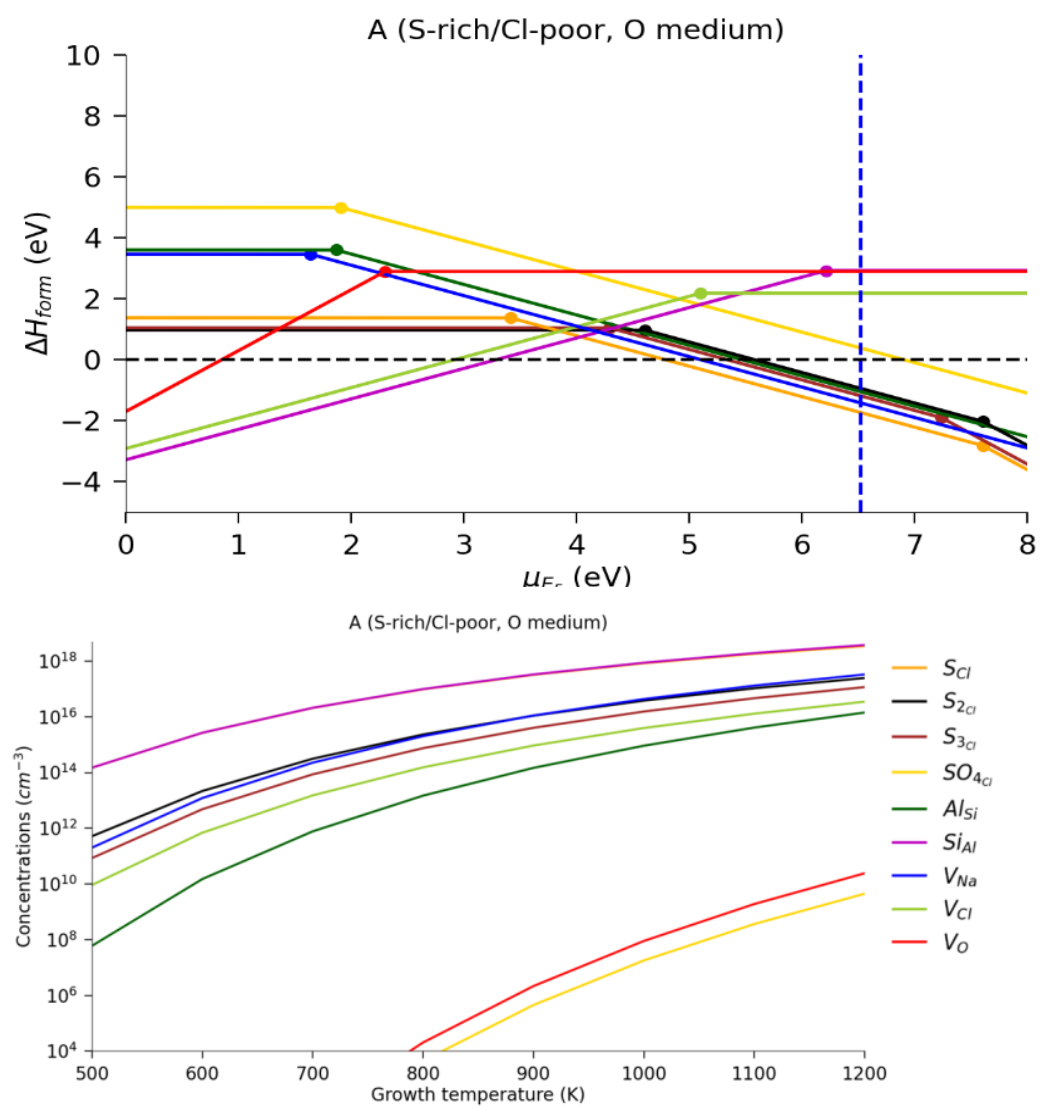

Figure 3. Computed defect energy formation (top) and defect concentrations (bottom) of simple point defects under the S-rich/Cl-poor/Omedium synthesis conditions $(\boldsymbol{A})$ (the concentrations $S_{C l}$ and $S_{i l}$ defects are perfectly superimposed). The vertical blue-dashed line is the computed band gap. Standard $T_{\text {grow }}=1200 \mathrm{~K}$

One should mention here that the $\mathrm{SO}_{4 \mathrm{Cl}}$ defect in A conditions is so high in enthalpy that its concentration is expected to be very low. This is confirmed by the calculated concentrations of defects versus the synthesis temperature in Figure 3. Namely, due to the insulating nature of the host material, the Fermi level adjusts itself so that the charges of the defects self-compensate in a Kröger-Vink manner. In that condition and using the mentioned equations in SI, the Fermi level $\left(E_{F}^{\text {grow }}\right)$ at $T_{\text {grow }}=$ $1200 \mathrm{~K}$ is around $\sim 4.10 \mathrm{eV}$. In that case, the defects concentrations of $S i_{A l}$ and $\mathrm{S}_{\mathrm{Cl}}$ are two orders of magnitude higher than $S_{2_{C l}}$ and $\mathrm{V}_{\mathrm{Na}}$. The other defects in lower concentrations are unlikely to be formed. In this atmosphere at $1200 \mathrm{~K}, \mathrm{Si}_{\mathrm{Al}}$ and $\mathrm{S}_{\mathrm{Cl}}$ have the highest defect concentrations $\left(\sim 10^{18} \mathrm{~cm}^{-3}\right)$ followed by $\mathrm{V}_{\mathrm{Na}}, S_{2_{C l}}$ and $S_{3_{C l}}\left(\sim 10^{16}\right.$ and $\left.10^{17} \mathrm{~cm}^{-3}\right)$.

Under the $\boldsymbol{B}$ synthesis conditions, the same reasoning applies. Namely, the dopability domain is shifted towards lower energies compared to A, still constricted, and still delimited by the formation enthalpies of $\operatorname{Si}_{\mathrm{Al}}\left(\mu_{E_{F}} \sim 2 \mathrm{eV}\right)$ and $\mathrm{V}_{\mathrm{Na}}\left(\mu_{E_{F}} \sim 3.5 \mathrm{eV}\right)$ (Figure 5). $\mathrm{V}_{\mathrm{Na}^{+}}(\varepsilon(0 /-1) \sim 1.75 \mathrm{eV})$ is the most favorable defect with a concentration three orders of magnitude higher than the second most probable defect, $\mathrm{SO}_{4}{ }^{2-}$ replacing $\mathrm{Cl}^{-}(\varepsilon(0 /$ $-1) \sim 1.90 \mathrm{eV}$ ). In that atmosphere, it is very unlikely to replace $\mathrm{Cl}$ by a (poly)sulfide $\left(\mathrm{S}, \mathrm{S}_{2}\right.$, or $\mathrm{S}_{3}$ ) (formation enthalpy higher than $8 \mathrm{eV}$ for these species at $\mathrm{Cl}$ site). As depicted in Figure 4, their calculated concentrations for a $T_{\text {grow }}$ higher than $1000 \mathrm{~K}$ is at least ten orders of magnitude less than the sulfate $\left(\mathrm{SO}_{4}\right)$ form! The later statement is of great importance and fully justifies the crucial choice of the chemical potential to perform a defect formation energy study and account for experiment. Clearly, it also implies the crucial choice of the oxidation/reduction conditions during the synthesis to stabilize cationic and anionic $\mathrm{S}$ ions. Since $\mathrm{SO}_{4}^{2-}$ is clearly present in large amounts in the XPS spectrum displayed in Figure $\mathbf{2}$ as well as mono/poly sulfur species, it means that synthesis conditions used for the preparation of hackmanite for instance $\left(850^{\circ} \mathrm{C}\right.$ for $8 \mathrm{~h}$ under reducing atmosphere $\left(\mathrm{Ar} / \mathrm{H}_{2} ; 95 / 5\right)$ with Zeolite $4 \mathrm{a}, \mathrm{NaCl}$ and $\mathrm{Na}_{2} \mathrm{SO}_{4}$ as precursor) have to be regarded as intermediate between hypothetical conditions $\mathbf{A}$ and $\mathbf{B}$, thus giving rise to the observation of multiple oxidation states of $\mathrm{S}$ and explaining the complexity of collected XPS spectra. 

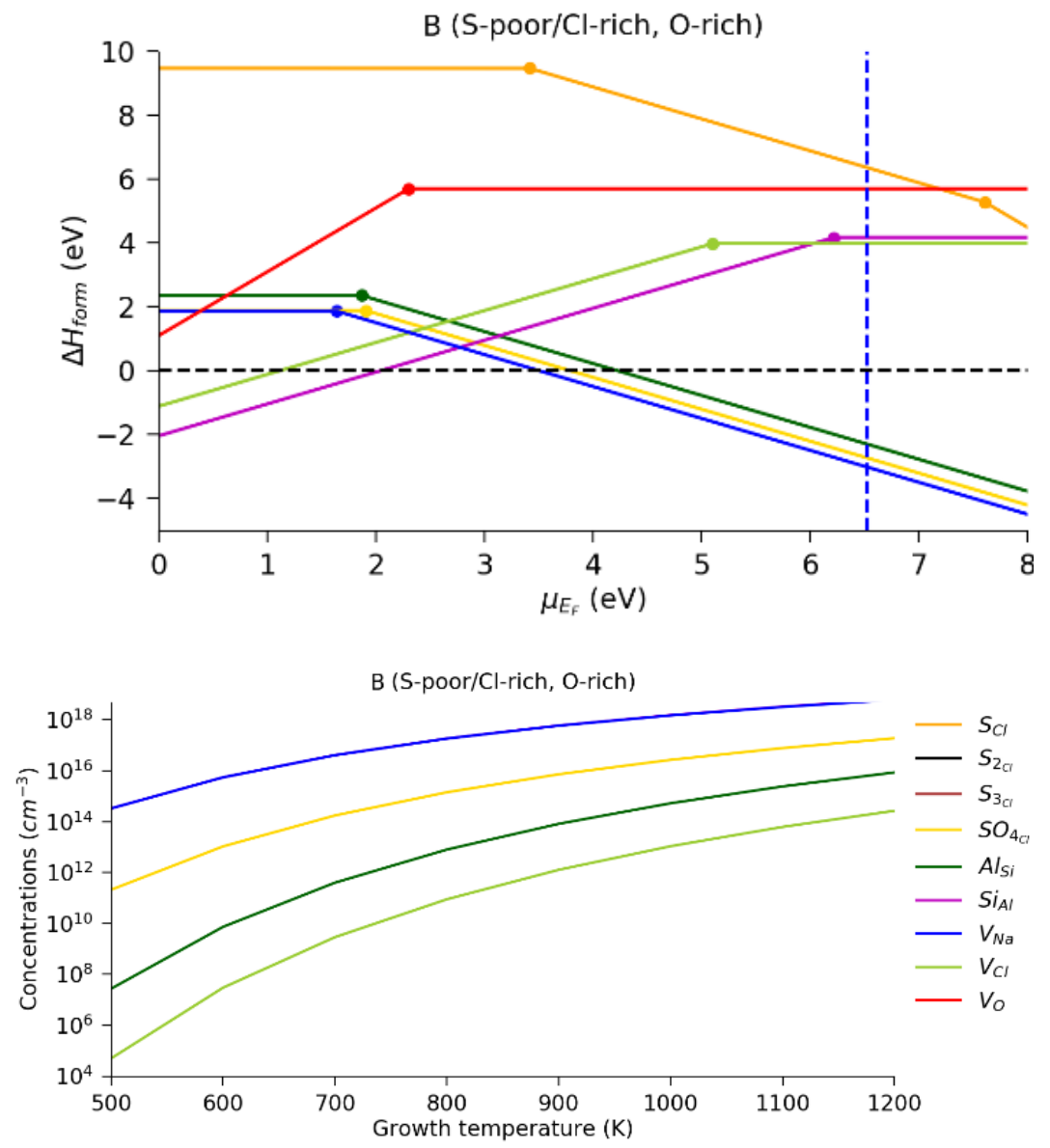

Figure 4. Computed defect energy formation of simple point defects (top) and defect concentrations (bottom) under the S-poor/Cl-rich/Orich synthesis condition $(\boldsymbol{B})$ (the concentrations $V_{N a}$ and $S i_{A l}$ defects perfectly superimposed). The vertical blue-dashed line is the computed band gap. Standard

Trow

$=$ 1200

\section{Complex defects}

So far, defects energy formation were calculated in the sodalite $\mathrm{Na}_{4}\left(\mathrm{Al}_{3} \mathrm{Si}_{3} \mathrm{O}_{12}\right) \mathrm{Cl}$ host lattice for isolated and non-interacting point defects. Of course, for obvious charge balance considerations and the natural attraction between positively and negatively charged defects, there are very high suspicions that the substitution of chloride by a (poly)sulfide often comes along with a vacancy of chlorine in its immediate neighborhood. Therefore, three defect complexes have been envisioned in addition to isolated ones. The complexes considered are made of a chlorine vacancy $V_{C l}$ and a sulfur/sulfide substitution in the next $\beta$-cage and are noted $V_{C l}+S_{C l} / S_{2 C l} / S_{3 C l}$. In $\boldsymbol{B}$ synthesis conditions, since it is both $\mathrm{S}$-poor and Cl-rich, these defects are not favored at all and their defect formation energies are very high (more than $10 \mathrm{eV}$ ). The $\boldsymbol{A}$ synthesis conditions are much more favorable for their formation. As one can see in Figure 5, the formation enthalpies are very low, indicating a priori high concentrations of each complex. Consequently, as concluded previously, S, $S_{2}$ and $S_{3}$ entities are supposed to coexist in $\mathbf{A}$ conditions in sodalite with a priori a lesser concentration for $S_{3}$, than $S_{2}$ and $S$ due to their relative formation energy. Importantly, in the $\sim 3.5-5 \mathrm{eV}$ energy range, these defect complexes would be neutral suggesting $\left(S_{n}\right)^{2-}$ species $(n=1,2$ or 3$)$ coupled with a single charged chlorine vacancy $\left(e . g . S_{C l}^{\prime}(q=-1)+V^{\circ}{ }_{C l}(q=\right.$ $+1)$ or $\left(S_{n}\right)_{C l}^{\prime}(q=-1)+V_{C l}^{\circ}(q=+1)$ in the Kroger-Vink notation).

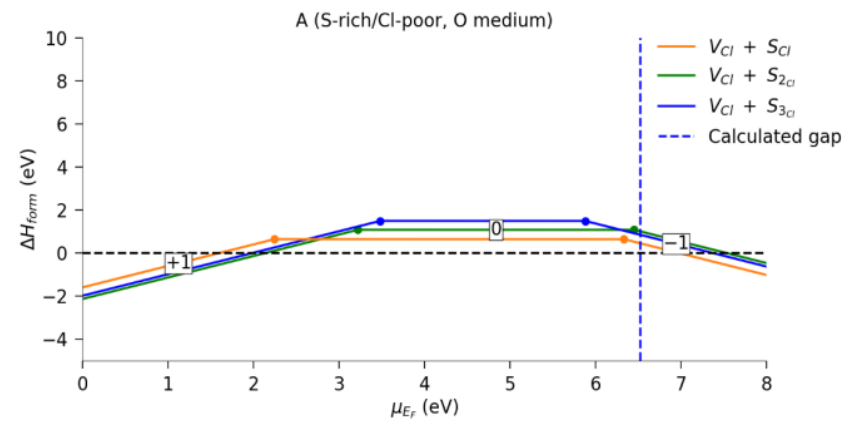

Figure 5. Defect energy formation of complex point defects under the S-rich/Cl-poor/O-medium medium synthesis condition (A).

\section{Conclusion}

It is well known that $\mathrm{Na}_{4}\left(\mathrm{Al}_{3} \mathrm{Si}_{3} \mathrm{O}_{12}\right) \mathrm{Cl}$ sodalite has the propensity to accommodate various sulfur-based species in place of chloride anions. Calculations clearly demonstrate here that $\mathrm{S}_{\mathrm{Cl}},\left(\mathrm{S}_{2}\right)_{\mathrm{Cl}}$ and $\left(\mathrm{S}_{3}\right)_{\mathrm{Cl}}$ defects might coexist since their formation enthalpies are quite similar. This fully accounts for the complexity of XPS spectra collected on hackmanite (but also on non-photochromic S-doped sodalite) and suggests that attempts to experimentally stabilize separately $S,\left(S_{2}\right)$ dimers or $\left(S_{3}\right)$ trimers will be deemed to fail, or simply doomed. Nevertheless, their relative 
concentrations can probably be tuned as a function of the synthesis conditions, explaining the blue, yellow or green colors of sodalite. In the specific case of $\mathrm{Na}_{4}\left(\mathrm{Al}_{3} \mathrm{Si}_{3} \mathrm{O}_{12}\right) \mathrm{Cl}$ hackmanite (where $\left(\mathrm{SO}_{4}\right),\left(\mathrm{SO}_{3}\right)$ and $(\mathrm{S})$ species cohabit), the colorless appearance in its ground state and the purple tint in its photogenerated state advocate that i) $\left(\mathrm{S}_{\mathrm{n}}\right)^{-}$anions are in too low a concentration to play the role of chromophore to generate a blue, yellow or green color, ii) $\left(\mathrm{S}_{n}\right)^{2-}$ species do not absorb in the visible range (as well as $\left(\mathrm{SO}_{4}\right)^{2-}$ and $\left(\mathrm{SO}_{3}\right)^{2-}$ entities) and consequently cannot induce a coloring effect in sodalite, and iii) $\left(\mathrm{S}_{\mathrm{n}}\right)^{\mathrm{x}} \mathrm{Cl}-\mathrm{Vx}_{\mathrm{Cl}}$ defect complexes, commonly named $\mathrm{V}_{\mathrm{Cl}^{\mathrm{x}}}$ color centers ( $\mathrm{F}$ centers), are at the origin of the photo-induced colors of hackmanite and have to be regarded as single entities and not two separated individual ones, i.e. $\left(\mathrm{S}_{\mathrm{n}}\right)^{\mathrm{x}_{\mathrm{Cl}}}$ and $\mathrm{Vx}_{\mathrm{Cl}}$.

\section{ACKNOLEDGMENTS}

The authors acknowledge Dr. Maria Teresa Caldes for helpful discussions. CL, AS and RS thank the CCIPL (Centre de Calculs Intensifs des Pays de la Loire) for computational resources. CL and RS thank the CNRS and Région Pays de la Loire for supporting the "Etoile Montante : CLIC" project.

\section{Supplementary Information}

The Supporting Information is available free of charge on the ACS website.

It includes the procedure to determine the chemical potentials, relevant experimental and simulated data, density of states together with the band structure of the host matrix and the charge transition levels.

\section{References}

(1) Phillips, W. Properties of Cathodochromic Sodalite. J. $\begin{array}{lllll}\text { Electrochem. } \quad \text { Soc. 1970, } 117 & \text { (12), } 1557 .\end{array}$ https://doi.org/10.1149/1.2407383.

(2) Gaft, M.; Panczer, G.; Nagli, L.; Yeates, H. Laser-Induced Time-Resolved Luminescence of Tugtupite, Sodalite and Hackmanite. Phys. Chem. Miner. 2009, 36 (3), 127-141. https://doi.org/10.1007/s00269-008-0263-1.

Fleet, M. E.; Liu, X. X-Ray Absorption Spectroscopy of Ultramarine Pigments: A New Analytical Method for the Polysulfide Radical Anion S3 - Chromophore. Spectrochim. Acta - Part B At. Spectrosc. 2010, 65 (1), 75-79. https://doi.org/10.1016/j.sab.2009.11.008.

(4) Kowalak, S.; Pawłowska, M.; Miluśka, M.; Strózyk, M.; Kania, J.; Przystajko, W. Synthesis of Ultramarine from Synthetic Molecular Sieves. Colloids Surfaces A Physicochem. Eng. Asp. 1995, 101 (2-3), 179-185. https://doi.org/10.1016/0927-7757(95)03153-5.

(5) Gobeltz-Hautecoeur, N.; Demortier, A.; Lede, B.; Lelieur, J. P.; Duhayon, C. Occupancy of the Sodalite Cages in the Blue Ultramarine Pigments. Inorg. Chem. 2002, 41 (11), 2848-2854. https://doi.org/10.1021/ic010822c.

(6) Reinen, D.; Lindner, G. G. The Nature of the Chalcogen Colour Centres in Ultramarine-Type Solids. Chem. Soc. $\begin{array}{llll}\text { Rev. 1999, } 28 \text { (2), } & \text { 75-84. }\end{array}$ https://doi.org/10.1039/a704920j.

(7) Arieli, D.; Vaughan, D. E. W.; Goldfarb, D. New Synthesis and Insight into the Structure of Blue Ultramarine
Pigments. J. Am. Chem. Soc. 2004, 126 (18), 5776-5788. https://doi.org/10.1021/ja0320121.

(8) Clark, R. J. H.; Dines, T. J.; Kurmoo, M. On the Nature of the Sulfur Chromophores in Ultramarine Blue, Green, Violet, and Pink and of the Selenium Chromophore in Ultramarine Selenium: Characterization of Radical Anions by Electronic and Resonance Raman Spectroscopy and the Determination of Their. Inorg. Chem. 1983, 22 (19), 2766-2772. https://doi.org/10.1021/ic00161a024.

(9) Colinet, P.; Gheeraert, A.; Curutchet, A.; Le Bahers, T. On the Spectroscopic Modeling of Localized Defects in Sodalites by TD-DFT. J. Phys. Chem. C 2020, 124 (16), 8949-8957. https://doi.org/10.1021/acs.jpcc.0c00615.

(10) Hodgson, W. G.; Brinen, J. S.; Williams, E. F. Electron Spin Resonance Investigation of Photochromic Sodalites. J. Chem. Phys. 1967, 47 (10), 3719-3723. https://doi.org/10.1063/1.1701527.

(11) Curutchet, A.; Le Bahers, T. Modeling the Photochromism of S-Doped Sodalites Using DFT, TDDFT, and SAC-CI Methods. Inorg. Chem. 2017, 56 (1), 414-423.

https://doi.org/10.1021/acs.inorgchem.6b02323.

Williams, E. F.; Hodgson, W. G.; Brinen, J. S. Synthetic Photochromic Sodalite. J. Am. Ceram. Soc. 1969, 52 (3), 139-144. https://doi.org/10.1111/j.11512916.1969.tb11200.x.

(13) Kirk, R. D. The Luminescence and Tenebrescence of Natural and Synthetic Sodalite. Am. Mineral. 1955, 40 (1-2), 22-31.

(14) Medved, D. B. The Optical Properties of Natural and Synthetic Hackmanite. J. Chem. Phys. 1953, 21 (7), 13091310. https://doi.org/10.1063/1.1699204.

(15) Norrbo, I.; Curutchet, A.; Kuusisto, A.; Mäkelä, J.; Laukkanen, P.; Paturi, P.; Laihinen, T.; Sinkkonen, J.; Wetterskog, E.; Mamedov, F.; et al, Solar UV Index and UV Dose Determination with Photochromic Hackmanites: From the Assessment of the Fundamental Properties to the Device. Mater. Horizons 2018, 5 (3), 569-576. https://doi.org/10.1039/c8mh00308d.

(16) Irie, M. Photochromism: Memories and Switches Introduction. Chem. Rev. 2000, 100 (5), 1683-1684. https://doi.org/10.1021/cr980068l.

(17) Kresse, G.; Furthmüller, J. Efficiency of Ab-Initio Total Energy Calculations for Metals and Semiconductors Using a Plane-Wave Basis Set. Comput. Mater. Sci. 1996, 6 (1), 15-50. https://doi.org/10.1016/09270256(96)00008-0.

(18) Kresse, G.; Joubert, D. From Ultrasoft Pseudopotentials to the Projector Augmented-Wave Method. Phys. Rev. $B$ Condens. Matter Mater. Phys. 1999, 59 (3), 1758-1775. https://doi.org/10.1103/PhysRevB.59.1758.

(19) Kresse, G.; Furthmüller, J. Efficient Iterative Schemes for $\mathrm{Ab}$ Initio Total-Energy Calculations Using Plane-Wave Basis Set. Phys. Rev. B 1996, 54 (16), 11169-11186. https://doi.org/10.1021/acs.jpca.0c01375.

(20) Perdew, J. P.; Burke, K.; Ernzerhof, M. Generalized Gradient Approximation Made Simple. Phys. Rev. Lett. 1996, 77 (18), 3865-3868. https://doi.org/10.1103/PhysRevLett.77.3865.

(21) Heyd, J.; Scuseria, G. E. Efficient Hybrid Density Functional Calculations in Solids: Assessment of the Heyd-Scuseria-Ernzerhof Screened Coulomb Hybrid Functional. J. Chem. Phys. 2004, 121 (3), 1187-1192. 
https://doi.org/10.1063/1.1760074.

(22) Norrbo, I.; Gluchowski, P.; Hyppänen, I.; Laihinen, T.; Laukkanen, P.; Mäkelä, J.; Mamedov, F.; Santos, H. S.; Sinkkonen, J.; Tuomisto, M.; Viinikanoja, A.; Lastusaari, M. Mechanisms of Tenebrescence and Persistent Luminescence in Synthetic Hackmanite Na8Al6Si6024(Cl,S)2. ACS Appl. Mater. Interfaces 2016, $8 \quad$ (18), 11592-11602. https://doi.org/10.1021/acsami.6b01959.

(23) Péan, E.; Vidal, J.; Jobic, S.; Latouche, C. Presentation of the PyDEF Post-Treatment Python Software to Compute Publishable Charts for Defect Energy Formation. Chem. Phys. Lett. 2017, 671, 124-130. https://doi.org/10.1016/j.cplett.2017.01.001.

(24) Stoliaroff, A.; Jobic, S.; Latouche, C. PyDEF 2.0: An Easy to Use Post-Treatment Software for Publishable Charts Featuring a Graphical User Interface. J. Comput. Chem. 2018, 39 (26), 2251-2261. https://doi.org/10.1002/jcc.25543.

(25) Stoliaroff, A.; Latouche, C. Accurate Ab Initio Calculations on Various PV-Based Materials: Which Functional to Be Used? J. Phys. Chem. C 2020, 124 (16), 8467-8478. https://doi.org/10.1021/acs.jpcc.9b10821.

(26) Lany, S.; Zunger, A. Accurate Prediction of Defect Properties in Density Functional Supercell Calculations. Model. Simul. Mater. Sci. Eng. 2009, 17 (8). https://doi.org/10.1088/0965-0393/17/8/084002.

(27) Kumagai, Y.; Oba, F. Electrostatics-Based Finite-Size Corrections for First-Principles Point Defect Calculations. Phys. Rev. B - Condens. Matter Mater. Phys. 2014, $89 \quad$ (19). https://doi.org/10.1103/PhysRevB.89.195205.

(28) Burstein, E. Anomalous Optical Absorption Limit in InSb. Phys. Rev. 1954, 93 (3), 632-633. https://doi.org/10.1103/PhysRev.93.632.

(29) Moss, T. S. The Interpretation of the Properties of Indium Antimonide. Proc. Phys. Soc. Sect. B 1954, 67 (10), 775-782. https://doi.org/10.1088/0370$1301 / 67 / 10 / 306$.

(30) Lany, S.; Raebiger, H.; Zunger, A. Magnetic Interactions of $\mathrm{Cr}-\mathrm{Cr}$ and Co-Co Impurity Pairs in $\mathrm{ZnO}$ within a BandGap Corrected Density Functional Approach. Phys. Rev. B - Condens. Matter Mater. Phys. 2008, 77 (24), 9-12. https://doi.org/10.1103/PhysRevB.77.241201.

(31) Stoliaroff, A.; Jobic, S.; Latouche, C. New Insights into the Determination of Maximum Chemical Potentials to Account for Alkali Doping in $\beta$-In2S3 by $\mathrm{Ab}$ Initio Calculations. Comput. Mater. Sci. 2019, 168 (June), 221228. https://doi.org/10.1016/j.commatsci.2019.06.011. 
TOC Graphic

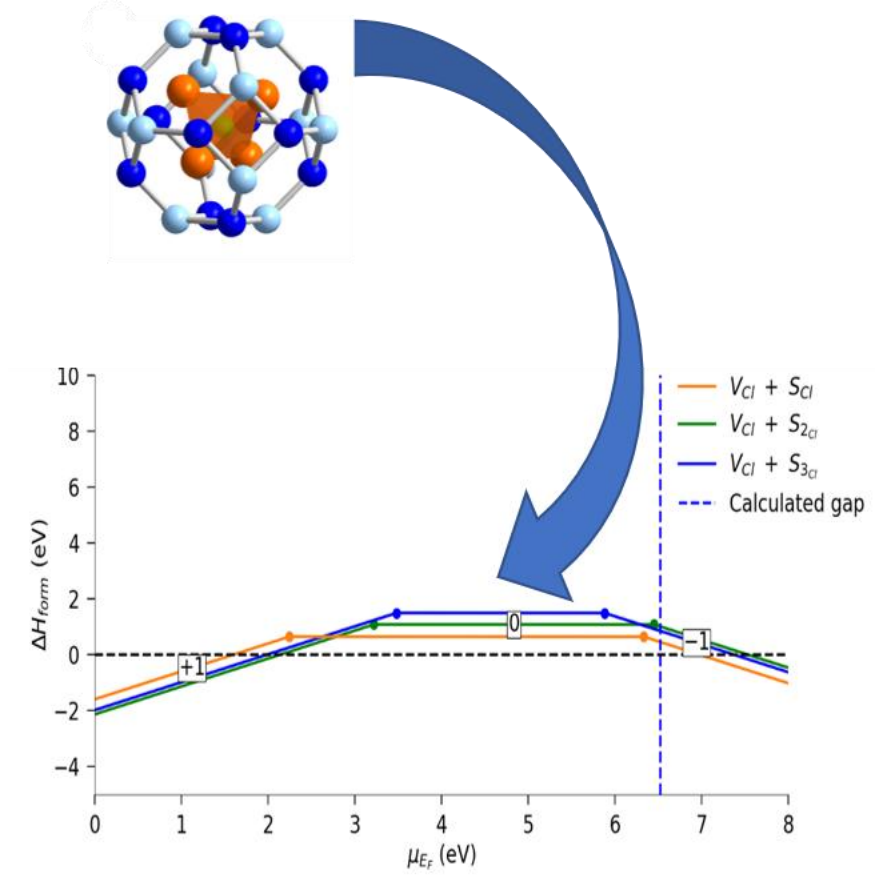

9 